David Movrin

Ljubljana

\title{
AL' PRI NJIH SRCE LEDENO SE OGREJE, SAM NE VE
}

Težave $\mathrm{z}$ razumevanjem literature, glede katerih se pevec $\mathrm{v}$ gornjem verzu pritožuje že nad lastnimi sodobniki, začnejo sorazmerno s časovno oddaljenostjo avtorja in bralca naraščati malodane eksponentno. Ravno zato literarna zgodovina znova in znova poudarja, kako je eden najbolj temeljnih pogojev za celostno razumevanje besedila prav poglobitev $\mathrm{v}$ kontekst, $\mathrm{v}$ katerem je nastalo. Nujnost tega početja se od izdelka do izdelka kajpak razlikuje: večino lahko bralec v zadostni meri razume že s pomočjo osnovnega pregleda nad svetovno zgodovino in literaturo, pri nekaterih pa je sporočilo jasno celo brez vsakršnega aparata. Juvenalov tekst ne spada $v$ nobeno izmed tovrstnih enostavnih kategorij.

$\mathrm{Na}$ koncu drugega tisočletja smo pri stiku $z$ njegovo satiro namreč kar $\mathrm{v}$ trojni zagati. Že takoj na začetku nas izdajo lastna ušesa: ta $v$ primerjavi $\mathrm{z}$ ušesi rimskega poslušalca iz prvega stoletja niso neobčutljiva le za dolžino vokalov, temveč v dobršni meri tudi za zven posameznih besed in njihove medsebojne povezave. Stavek

Nemo tamen studiis indignum ferre laborem

cogetur posthac, nectit quicumque canoris

eloquium vocale modis laurumque momordit.

bo tako najbrž le redkokoga spravil $\mathrm{v}$ smeh zaradi tega, ker mogočnemu, napihnjenemu laurumque sledi sočno onomatopoetični in nekoliko nesmiselni reduplicirani perfekt momordit, medtem ko je v nasprotju $\mathrm{z}$ nami antično publiko že samo ob takšnih filigranskih podrobnostih najbrž kar poščegetalo pod rebri. ${ }^{1}$ Poleg ušes pa nas ovira tudi naš lastni smisel za humor: v času, ki je - po Veynu - vkleščen $v$ estetiko intenzivnosti, je koža že dolgo tega čez in čez postala podplat in so ji zato iz dneva v dan potrebni močnejši dražljaji. Nič čudnega ni v tem, da ostaja Robov Deseti brat, ki je še v prvi polovici stoletja predstavljal vrh tovrstne domače literature, danes skoraj brez odziva; operae theatrales iz angloameriških nanizank nas večer za večerom razvajajo do stopnje, ko se nam še smejati ni več treba.

Vendar je pri teh dveh ovirah naša okvara že nekako organska in pomoči zato tudi ni. Drugače je $z$ zadnjo, $z$ aktualnostjo Juvenalovih satir. Te namreč računajo na bralca, ki je domač v mitologiji in zgodovini, ki suvereno obvladuje sočasno kulturno dogajanje in ki obenem spremlja družabno in politično življenje, zaradi česar aluzij na najneznatnejše drobce $z$ vseh koncev in krajev kar mrgoli. Ker pa so se akterji na teh področjih $v$ dveh tisočletjih kajpak zamenjali, lahko danes ob verzih

Nam si Pieria quadrans tibi nullus in umbra

ostendatur, ames nomen victumque Machaerae

et vendas potius commissa quod auctio vendit

stantibus, oenophorum tripedes armaria cistas,

Alcitheon Pacci, Thebas et Terea Fausti.

lahko samo nemočno skomigujemo z rameni. Pieria, to še nekako gre, ampak kdo naj bi bil ta Machaera? Kdo sta Paccius in Faustus, in kaj na svetu imajo z njima opraviti

\footnotetext{
' Primere navaja in analizira G.O. Hutchinson v Latin Literature from Seneca to Juvenal. Clarendon Press, Oxford 1993, str. 98 in nasl.
} 
Alcithoe, Thebes in Tereus? Le s pomočjo intuicije in morebitnih sholij lahko strokovnjak bolj ali manj ugane, da gre pri prvem za dražbarja, pri drugih dveh za danes neznana trageda in pri ostalih za naslove njunih - po Juvenalovem mnenju očitno zanikmih - izdelkov. Do vsega tega, kar je v antiki konotiralo že samo ime, se je treba danes torej mukoma prikopati preko opomb $v$ drobnem tisku. Toda kljub temu, da verjetno ni nič bolj neprijetnega, kot je razlaganje kake šale, bomo ob drugem ali tretjem branju satiro vendarle vsaj razumeli in $\mathrm{z}$ malo sreče in dobre volje tako lahko občutili tudi del tistega veselja, ki so ga te vrstice sprožile nekoč.

Zaradi vsega tega je tudi ta prevod ujet v sțaro dilemo o tem, do kakšne mere je smiselno izvirnik posodabljati. Po eni strani je nasičenost $z$ mnogoterimi aluzijami in nadomeščanje človeških tipov $z$ osebnimi imeni za Juvenala tako značilno, da bi s popolnim izločanjem vsega tega njegov slog osiromašili do neprepoznavnosti. Gledano $\mathrm{z}$ druge strani pa bi filološko zvest prevod laičnega bralca (in ti so pri prevajanju nedvomno ciljna publika, saj latinist lahko uživa ob izvirniku) $\mathrm{z}$ množico opomb najbrž odbil. Tako pravi tudi Gilbert Highet ${ }^{2}$ v zaključku svoje monografije: "To, kar [Juvenal danes] najbolj potrebuje, sta en ali dva dobra, sodobna, prirejena in verzificirana prevoda - narejena brez pedantnosti in brez (ali s posodabljanjem) zastarelih aluzij [...]." Na podoben, čeprav mestoma mogoče kar nekoliko preveč radikalen pristop naletimo še v prevodu ameriškega filologa Petra Greena. ${ }^{3}$ Sam sem se, hoteč upoštevati oba vidika, skušal držati srednje poti in zato najbolj obskurna osebna in krajevna imena nadomestil s pojmi, ki jih predstavljajo, zraven pa iz dosegljivih izdaj ${ }^{4}$ povzel opombe, ki olajšajo razumevanje preostalih. Za spodbudo in kritičen pregled prevoda se na tem mestu zahvaljujem profesorici Katji Pavlič Škerjanc in profesorju Kajetanu Gantarju; brez njjju ga ne bi ne začel in ne končal.

Danes, ko so se klasičnim filologom končno spet odprle možnosti za delo v šolstvu, se skupaj z evforijo znova pojavljajo tudi prastari - kot kaže pričujoča satira pedagoški problemi. Za njihovo uspešno reševanje je najprej potrebna distanca, to pa po Franklovem receptu najučinkoviteje vzpostavlja prav humor. Zaradi tega upam, da bo Juvenal tudi sodobnega bralca ogrel $\mathrm{z}$ duhovitostjo, $\mathrm{s}$ katero je svoj čas pritegnil cerkvene očete in sta ga zaradi nje občudovala Dante in Boccaccio, ter $\mathrm{z}$ uporabnostjo, ki jo je bil v njegovi - sicer deseti - satiri sposoben videti Hamlet:

'Kaj čitate, kraljevič?'

'Besede, besede, besede.'

'Za kaj pa gre?'

'Kdo gre?'

'To menim, kakšna je vsebina knjige, ki jo čitate, kraljevič.'

'Obrekovanja, gospod: zakaj ta satirični lopov pravi tukaj, da imajo starci sive brade, da so jim lica nagubana, da se jim cedi iz oči jantar in mačja smola; da imajo velikansko pomanjkanje duhovitosti, poleg tega pa zelo šibka stegna: o vsem tem sem

2 Gilbert Highet: Jwenal the Satirist. Oxford University Press, London 1962, str. 232.

${ }^{3}$ Poljudno napisano apologijo tovrstne prakse podaja v obsežnem uvodu h knjigi Juvenal: The Sixteen Satires. Penguin Books, London 1974, str. 6I in nasl.

\footnotetext{
${ }^{4}$ Poleg že citiranega Greenovega prevoda so tu še:

Juvenal and Persius. Angleski prevod in opombe G.G. Ramsay, The Loeb Classical Library, Harvard University Press, Massachusetts 1950.

Iuvenal, D.I.: Saturae. Opombe Andreas Weidner, B.G. Teubner, Leipzig 1889.

M.C. Howatson, lan Chilvers: The Concise Oxford Companion to Classical Literature. Oxford

University Press, Oxford 1993.
} 
sicer globoko in iskreno prepričan, vendarle se mi ne zdi spodobno, da se kaj takega napiše; zakaj vi samí, gospod, bi prišli v moja leta, če bi mogli lesti rakovo pot.."

\section{Satira VII}

Cezar poslednji je up umetnikov, up učenjakov, on je Kamene otožne edini $v$ tej dobi opazil.

$\mathrm{V}$ dobi, ko pesniki slavni najemajo v mestih pekarne, drugi si jemljejo terme $\mathrm{v}$ zakup nekje na deželi, tretjih pa spet ni sram služíti si kruh med klicarji.

$\mathrm{V}$ dobi, ko Klio je lačna iz svetih dolin Aganipe $\mathrm{k}$ dražbarjem šla živet. Zares, če v Piérije senci $\mathrm{ni}$ in ni beliča, bo zate najbolje, če sprejmeš službo (in zraven še plačo) pri izklicevalcu na dražbi, $\mathrm{v}$ bitko se vročo podaš, $s$ kladívom čim dražje prodajaš množicam skrinje, omare, trinožnike, vrče ter drame tretjerazrednih pisunov o stokrat prežvečenih temah. Bolje, da to počneš, kot da lažeš sodnikom, ter trdiš: "Videl sem," tudi ko nisi, kot delajo novopečeni plemiči, prišleki z Vzhoda, ki tu so povzpeli se naglo, vendar nam njihov izvor odrgnjeni kažejo gležnji.

Toda odslej nihče, ki v pesem zvenečo prepleta govor, nihče, ki je ugriznil v Apolonov lovorov venec, $\mathrm{k}$ delu, ki njega ni vredno, ne bo več nikoli prisiljen. Mladi, na delo! Spodbuja in spremlja vas milost vladarja, milost, ki v svoji dobroti le snov in povod potrebuje. Če pa morda pomoči iz drugih se virov nadejaš, $\mathrm{z}$ mislimi nanjo ustvarjaš, ko polniš z besedami novo stran pergamenta, tedaj pač raje polena zahtevaj, delo pa Venere možu pokloni, drugače pa knjige

skrij, zakleni ter pusti jih moljem in črvom za hrano. Zlomi pisalo iz trsta; uniči junaške pesnitve, plod prečutih noči, nesrečnik, ki v sobi podstrešni pesmi ustvarjaš, da z njimi bi lovor in kip si zaslužil. Jalovo upanje; tvoj bogati skopuh se naučil hváliti le je umetnost, se vsemu čuditi (kot dečki hvalijo ptico Junone). A čas, ko moč ti dopušc̆a morje in meč in motiko izbrati, ti naglo odteka.

Duh naveličan postane, Terpsíhoro starost preklinja, zraven pa svojo norost; peresa je vešča, a strada.

Glej zdaj, kako tvoj patron, zaradi katerega pustil tempelj si Muz in Apolona, pazi na svoje bogastvo. (Sam pesnikuje in misli, da $v$ tem tisočletju nemara kos mu je le še Homer.) Če kdaj želiš nastopiti, gnan od želje po slavi, ti $v$ ta namen bo posodil bajto umazano $\mathrm{v}$ kakem predmestju, $\mathrm{z}$ zabitimi vrati,

${ }^{5}$ W. Shakespeare: Hamlet; II,2. Prevedel Oton Župancið. 
kot da so vrata utrdbe, ki vojska jo vztrajno oblega. Znal bo po sobi postaviti sužnje in spremstvo številno; vzklikov in hvale po branju tako bo več kot zadosti. Nihče od njih pa najema klopi ne bo hotel prevzeti, sam plačeval boš za stole in sam za privzdignjeni oder, sam jih boš mukoma vračal takoj po koncu nastopa.

Mi pa ne nehamo s tem in pesmi ustvarjamo dalje, orjemo brazde po prahu, obračamo nerodovitno mivko obalno. Če kdaj odnehaš, te précej spet zgrabi sla po pisanju, po slavi, te $v$ zanko zadrgne in v tvojem srcu ostane na veke, kot neozdravljiva bolezen.

Pravega pesnika pa, ki vodi navdih ga edinstven, tega, ki znanih reči ne opeva, katerega pesmi niso kot lažen denar, suhoparne, osladne in plitke, (tega, ki zdaj se ga sicer ne spomnim, a vem, da obstaja), takšnega duh zaznamuje brezskrben, bridkóst mu je tuja, ljubi gozdove; kot tak je najbolj primeren, da pije vodo iz vira Aonk.

Kako naj prepeva otožna

Revščina tam v votlinah Piérije, sega po tirzu, zraven pa noč in dan jo telo po denarju sprašuje? Res je Horacij napisal "Juhej!" - a s polnim trebuhom! Kje naj prebiva navdih drugje kot pa v srcu, ki muči lastna ga pesem samo, vznemirja ga skrb ena sama, kadar Apolon s seboj ga ponese in z njim Dionizij?

Saj potrebuje duha, ki ne klecne pred ceno odeje, ako naj slika obličja bogov, vozove in konje, slika, kako Alekto straši junaškega Turna.

Kajti če sužnjev in strehe nad glavo ne imel bi Vergilij, tudi Eriniji kače bi vse popadale $z$ glave,

brez glasu bi tromba mogočna ostala. Kako naj danes traged dosega stvaritve nekdanjih, ko daje plašč in posodo zastavit, da delo do konca napiše? Numitor, revež, žal nima dovolj za prijatelja v stiski, vendar ima dovolj, da ljubici nosi darila.

Tudi denar za nakup domačega, krotkega leva skupaj je spraskal. Seveda, zverino hraniti, to stane nekajkrat manj kot meso za pesnikov strašni želodec.

S slavo Lukan zadovoljen tam v vrtu razkošnem počiva; kaj pa kakršnakoli že slava pomaga nekomu brez zapuščine bogate?

Na kup pridere vse mesto glas prijeten poslušat, ki bere Tebáido, ko Stacij svoj recital napove; saj množici s takšno sladkostjo pesem prevzame duha, da s pravo strastjo ji prisluhne. Potlej po koncu, ko ljudstvo navdušeno stole razdre, pa

Stacij bo spet gladoval, če Parisu, temu, ki pleše Cezarju večkrat na čast, ne proda besedila. Saj Paris daje odličja vojaška in on natika na roke pesnikom prstane zlate. Če plemič ti prošnjo odreče, 
prosi igralca! Morda postopaš po širnih predsobah

kakih mogočnikov? Ples te prefektu najavi, balet te pelje k tribunu! Zares, nevoščljiv ni treba ti biti temu, ki pesem redi ga; kdo ti bo danes Mecenas, kdo bo zdaj Prokulej, kdo danes bo Fabij in Kota, kdo ti bo Léntul? Le v njihovem času za delo nagrado

pravšnjo dobil bi. Takrat se je res splačalo decembra trezen ostati doma in mirno za mizo pisati.

$\mathrm{Vi}$, zgodovinarji, mislite mar, da vaše je delo plodnejše? Več čmila gre v nič, več časa v pogubo. Tisoči novih strani nastajajo, kup je vse višji, mere pri tem ne poznate, papir množite potratno. To pač zahteva obilje podatkov in zakon poklica. Vendar pa, kakšna bo žetev iz tega in kakšni sadovi? Kdo zgodovinarju dal bo, kolikor prejme novičar?

"Ah, zgodovinarji vsi so lenuhi, ki v senci ležijo."

No, pa povej, kaj pravnik dobi za trud na sodniji, kaj za svežnje debele, za akte, ki v njih jih prenaša?

Res, da besed mu ne zmanjka, še zlasti, ko upnik posluša, ali ko stranko je strah za pravdo sumljivo in naglo $\mathrm{z}$ bukvami svojimi tja med rebra pošteno ga dregne.

Kot kak meh tedaj laži bo puhal iz sebe, pljuval po prsih se. Njihove prave dohodke mogoče rad bi odkril? Premoženje voznika na dirkah v areni pravniških sto premoženj na kup nametanih odtehta!

Vstaneš, ko sede porota, da branil bi, Ajas bledični, sporno prostost siromaka pred topim, zabitim sodnikom.

Strgaj glasilke si, revež, da potlej lahko boš izmučen palmove veje zelene si v slavo pribil na stopnišče.

Kakšna bo tvoja nagrada? Kak kos gnjati posušene, drobcen slanik, čebula, plesniva kot v vojski, mogoče nekaj vodenega vina. Pri štirih si pravdah prislužiš en sam samcat zlatnik, a del (po dogovoru) hoče vsakdo ga imeti, ki kdaj ti je s pravnim nasvetom pomagal. Jasno, Emilij dobil bo toliko, kolikor hoče, tudi za slabši zagovor. Seveda, pred vrati stoji mu bronasta četverovprega, ki kip njegov jo upravlja, mrk, bojevit, $\mathrm{z}$ ukrivljenim kopjem, in $\mathrm{z}$ enim očesom bitko v daljavi motri ter nanjo pripravlja se $\mathrm{v}$ mislih.

Takšna razsipnost jih spravlja na kant, tako bo propadel tisti bahavi Tongilij, ki enkrat se v termah postavlja

$\mathrm{s}$ spremstvom (zamazanim $\mathrm{z}$ blatom) in s svojo bogato opremo, drugič spet sužnje mrcvari z nosilnico težko, $v$ kateri gre na trg kupovat si sužnje, srebro in posestva; zanj namreč jamči obleka iz drage škrlatne tkanine. Vendar se to izplača, škrlat in dragulji lovijo pravniku stranke; te gledajo zgolj na lepo obleko.

Splača se torej živeti razkošno, prek zmožnosti svojih, Rim zapravljivi nikomur $v$ teh dneh ne pristriže peruti.

Kaj, naj v govorništvo upam? Saj danes nihče Ciceronu 
pare prebite ne dal bi brez biserov svetlih na prstih!

Prvo, kar stranka pogleda, je: koliko sužnjev premoreš, koliko osvobojencev, in kje je nosilnica s spremstvom.

Tu je vzrok, da je Pavel za pravde najemal prekrasen prstan bleščeč, in zato je več kot ostali zaslužil.

Kajpak, kako naj mož zakrpan bo dober govornik?

Kdo bo odvetniku revnemu pravdo zahtevno zaupal?

Kdo ga bo sploh poslušal, četudi izvrstno jo brani?

$S$ pravom pri nas se služiti ne da, zateci se raje v Galijo, v Afriko, znano odvetniško mater, dojiljo.

Kaj, mladino učiš govoriti? Zares potrebuješ

prsi železne, ko razred mesari okrutne tirane.

Vsak stoje ponovi, kar sedé si v glavo je stlačil, eden za drugim ponavljajo isto, še verzi so isti! Stokrat prežvečena čorba učitelja sčasom ubije.

To, kako naj bo govor obarvan, katerega tipa

pravdo izbrati, na kaj paziti in kam bo nasprotnik streljal puščice - vse to bi vsakdo rad vedel, nihče pa plačati noče šolnine! "Šolnino zahtevaš? Povej mi, kaj pa sploh znam?" Seveda, učitelj je kriv, če ničesar $v$ prsih ne čuti arkadski mladenič, ko teden za tednom

"Hanibal strašni" v nesrečno mi trobi uho, pa naj slavni Punec razmišlja o tem, če nad Rim naj po zmagi odrine, z vojsko zavzame prestolnico, najsi po hudi nevihti moker kot miš se $z$ utrujeno vojsko vrti po deželi. "Česa bi vsega ne dal, da fantov bi oče poslušal tolikokrat ga kot jaz! Povej mi vsoto, dobiš jo!" To kričijo učitelji, potlej pa eden za drugim govore šolske pustijo, 'Razbojnika, 'Zastrupljevalca,' 'Govor o podlem soprogu' in druge pa kmalu zamenja govor na pravem sodišču, ki zopet jim žepe napolni.

Torej, če moj nasvet kaj velja, naj ta, ki je menjal senčno, lagodno življenje govornika s službo v razredu, prejšnje udobje pozabi, drugačno življenje ubere.

V vrsto za žito brezplačno naj gre, to zanj bo vsekakor glavni, najvišji dohodek. Ne vprašaj, za kakšne denarje

$\mathrm{v}$ petju in brenkanju glasbenik uri otroke veljakov; jezen na vse boš zmlel Teodorja "Retoriko" v kosce.

Stotine tisočev troši gospod, ko gradi kopališče, stotine nove stebrišče požre. (Naj tuhta ob dežju kdaj se nebo bo zjasnilo, naj vprego zamaže po blatu?

Je pa že bolje, da mule ohranijo čista kopita!)

Spet drugje poganja obednica, zraven pa stebri (marmor numidijski!) streho nastavljajo zimskemu soncu. Naj bodo stroški še takšni, prišel bo še kuharski mojster, z njim pa strežnik, ki z mnogo okusa jedi razpostavlja.

Kajpak, pri takšnih izdatkih stotak bo več kot zadosti Kvintilijanu; ko oče plačuje, takrat zanesljivo sin nazadnje prišel bo na vrsto. "Od kod pa potem vsa tista velika posestva dobil je Kvintilijan, kaj?" 
Pusti izjeme! Kdor srečo ima, je lep in pogumen,

srečni je moder in plave krvi, vzgojen je izvrstno, $\mathrm{s}$ črnih jermenov na čevlju pa sije mu mesec senatni.

Srečni je dober govornik in hkrati je spreten pri športu, poje pa krasno, celo če prehlad ga stiska za grlo.

Vse je odvisno od zvezd, ki ob rojstvu so tvojem sijale,

spremljale tvoje kričanje, ko rdeč si iz matere príšel.

$\mathrm{Da}$, če Fortuna želi, postal učitelj bo konzul, toda če hoče drugače, ta konzul bo znova učitelj.

Kaj pa Ventidij? In Tulij? Priznaj, obema so stale zvezde ob strani ter čudežna moč skrivnostne usode.

Sužnjem bo dala Usoda kraljestva, ujetim trumfe, vendar pa Srečni kljub temu redkéjši od bele je vrane. Mnogim bilo je žal odločitve za ničev in jalov stolček profesorski; to nam kaže Trasímahov konec, Kárina kaže Sekúnd. Atene, od vas je ubogi zgolj trobelike kozarec dobil, pred tem pa ničesar.

Zemlja naj lahno leži nad sencami staršev, bogovi, večna pomlad in vonj žafrana naj žare prekriva.

Kdo je določil, naj mesto, ki vedno ga imel je roditelj vzame učitelj? Ahil, že velik, je v strahu pred šibo

$v$ hribih domačih prepeval; nikdar mu prišlo ni na misel repu učitelja pevca se drzno smejati. A danes Rufa in druge pretepajo njihovi lastni učenci, Rufa, ki znova in znova so rekli mu "Ciceron z Rone." Kdo bo Palájmonu plačal učenemu, kdo bo Keládu dal, kar učitelju gre? Vendár pa tudi od tega skromnega zneska - in manjši celo je od retorske plače svoje odgrizne poprej si varuh otrokov pohlepni, svoje odtrga očetov upravnik. Predaj se, Palajmon, kar barantaj, pristani na manj, tako kot krošnjarji, kadar prodajajo zimske obleke kadurške, dokler vsaj nekaj dobivaš. Samo da zaman zapravljene niso ure polnočne, ko v luknji sedel si, kjer bi ne maral vajencev svojih učiti noben kovač ali tkalec; $\mathrm{da}$, samo da zaman ti vohati ni bilo treba vseh svetilk učencev, zaradi katerih je bil ves Flak obledel in razbarvan ter Maron ves čm in sajast.

Kljub temu pa se plačo le redko dobi brez sodišča. Toda vseeno nalagajte, starši, učitelju stroge, krute predpise: obvlada naj slovnice zadnjo podrobnost, zna zgodovino, pozna vse prednike slavne, kot lastne nohte na prstih. Če kdaj, ko hiti v kopališče, slučajno križa vam pot, naj brž pove: kako se je reklo pestunji kralja Anhíza, odkod in katero imel je mačeho Ánhemol, koliko star Akést je umrl, koliko vrčev sicilskega vina razdal je Trojancem?

Naj oblikuje mladini značaj, kot lutki voščeni s palcem bi gnetel obraz; od njega zahtevajte, naj bo oče celotni skupini, tako da se kdo ne domisli 
iger sramotnih in šal. Povem vam, še zdaleč lahko ni

čuvati toliko fantov, oči in rok razpuščenih!

"Zanje poskrbi," bo slišal, "potem pa, ko leto konča se, plačo dobiš, ki voznik si z eno jo tekmo zasluži.

\section{OPOMBE K PREVODU}

v. 2 Kamene: Kamene so bile v rimski mitologiji sprva boginje studencev, po Andronikovem prevodu Odiseje pa so jih začeli enačiti z grškimi Muzami.

v. 6 Klio: Muza zgodovine. Aganipe: Muze so sicer živele na Olimpu, vendar so se rade zadrževale tudi ob Aganipi, izviru Hipokrene na Helikonu v Bojotiji (kị zaradi tega navdihuje pesništvo), in ob kastalijskem izviru na Parnasu v Fokidi.

v. 7 Pierije: Pokrajina v Makedoniji. Pieros, knez v makedonskem glavnem mestu Peli, je dal svojim devetim hčeram imena Muz; po drugi legendi je bil celo njihov oče.

v. 15 prišleki z Vzhoda: Sužnji iz Azije, ki so v Rimu napredovali celo do plemiškega naziva (eques):

v. 18 Apolonov lovorov venec: Simbol pesništva.

v. 25 Venere možu: Vulkanu, bogu ognja.

v. 29 lovor in kip: Doprsni kipi pesnikov so bili okrašeni $z$ lovorom (prim. Horacij, Ode 1.1.29).

v. 32 ptico Junone: Pava.

v. 37 tempelj Muz in Apolona: Verjetno gre za namig na knjižnici, ki sta ju ustanovila Avgust in njegova žena Livija $v$ templjih Apolona in Muz na Palatinu.

v. 59 iz vira Aonk: Iz Aganipe. Aonci so bili bojotijski staroselci, imenovani po starem heroju Aonu. Aonke so potemtakem Muze, ker prebivajo na (bojotijskem) Helikonu ob (bojotijski) Aganipi.

v. 60 po tirzu: Lahka, na gornjem koncu $z$ bršljanom ali trto ovita palica. Nosil jo je Bakh, ki je kot bog vina navdihoval pesnike.

v. 62 juhej: Tako Horacij v Odah (2.19.5) popisuje razbrzdane krike Bakhantk. Horacij je imel zaradi svojega radodarnega zaščitnika Mecenata naravnost sanjske pogoje za ustvarjanje: še misliti ni bilo, da bi moral kdaj stradati.

v. 68 Alekto: Prim. Vergilij, Eneida (7.445). Furija Alekto se je v sanjah prikazala kralju Turnu, ko pa se je ta rogal njenim prerokbam, je pobesnela:

$\mathrm{V}$ jezi srditi po takšni nesramnosti vzraste Alekto.

Sredi besede prevzame drget mladeniču ude, v strahu strmijo oči: Erinije sikanje spremlja toliko kač, tako strahotna se kaže prikazen.

v . 79 Lukan: Pesnik Mark Anaj Lukan (39-65) je bil nečak filozofa Seneke in družina je bila kar premožna, na kar tu namiguje Juvenal. Lukan je bil sprva Neronov zaupnik, kasneje pa je padel $v$ nemilost in verjetno se je zaradi prepovedi literarnega ustvarjanja leta 65 pridružil Pisonovi zaroti. Ta je propadla, Lukan pa je bil skupaj $\mathrm{z}$ očetom in obema stricema prisiljen $\mathrm{k}$ samomoru. Zapustil je nedokončan ep Pharsalia. 
v. 82 Stacij: Pesnik Publij Papinij Stacij (45-96) se je rodil v Neaplju, kasneje pa se je naselil $v$ Rimu ter bil v precej prijateljskih odnosih s cesarjem Domicijanom. Svoj ep Thebais je pisal kar dvanajst let, med tem časom pa je priredil več javnih recitalov. Verjetno mu ni šlo tako zelo slabo, kot nas želi Juvenal tu prepričati.

v. 86 Parisu: Paris je bil znan pantomimus (baletni plesalec), ki je bil leta 83 obtožen prešuštva $\mathrm{z}$ Domicijanovo ženo Domicijo ter usmrčen. Pisanje besedil zanj je res znak pomanjkanja; danes bi ga mogoče lahko primerjali s klepanjem scenarijev za hollywoodske žajfaste nadaljevanke.

v. 88 odličja vojaška: Poveljujoči častnik legije (tribunus) je po šestih mesecih službe avtomatično postal eques, 'vitez'. Cesar Klavdij je začel s častnimi imenovanji, tako da so equites lahko postali tudi ljudje, ki v vojski sploh niso služili (prim. Svetonij, Klavdij 25 in Plinij, Pisma 4.4), in poznanstva na dvoru so se zato dostikrat izkazala za koristnejša od dejanskih zaslug.

v. 93 Mecenas: Premožen plemič in zaščitnik umetnikov, še posebej Horacija. Enako Prokulej (prim. Horacij, Ode 2.2.5); Pavel Fabij Maksim je bil Ovidijev zaščitnik, podobno tudi Kota (prim. Ovidij, Pontska pisma 2.8), Publij Lentul Spinter pa je pomagal pri preklicu Ciceronovega izgnanstva.

v. 96 decembra: Saturnalije (od 17. do 19. decembra) so bile bučen karneval, med katerim so se sužnji lahko začasno obnašali, kot se jim je zahotelo.

v. 112 pljuval po prsih: Pljuvanje in močenje prsi s slino prinaša po stari vraži srečo ter odvrača zle uroke.

v. 115 Ajas bledični: Namig na tekmo med Odisejem in Ajantom za Ahilovo orožje. (lliada, $\Psi 754-784$ )

v. 118 palmove veje zelene: Odvetnik, ki je dobil tožbo, je imel pravico obesiti na svoja vrata palmove veje.

v. 119 kos gnjati posušene: Od strank s podeželja so odvetniki prejemali darila v naturalijah.

v. 124 Emilij: Emilij je bil očitno plave krvi. Leta 204 pr.Kr. so z zakonom (Lex Cincia) omejili dohodke odvetnikov.

v. 130 Tongilij: Ni znan.

v. 143 Pavel: Ni znan.

v. 149 v Galijo, v Afriko: Na začetku cesarske dobe so v Galiji, Hispaniji in Afriki začele cveteti šole govorništva.

v. 151 mesari okrutne tirane: $V$ starem Rimu retorika ni bila le praktična veščina, temveč tudi eden glavnih šolskih predmetov. Ostri govorniški napadi na samodržce in slavospevi njihovim morilcem so bili del učnega programa; danes se morda zdi čudno, da doba cesarstva te navade ni izkoreninila, vendar je bil šolski tiran vse preveč fantastičen in neresničen, da bi ga kdo lahko jemal resno. Iz neživljenjskosti predpisanih tem so se zato norčevali tudi številni satiriki.

v. 160 arkadski mladenič: Prebivalci grške pokrajine Arkadije so se imeli za najstarejše Zemljane; kljub temu njihova razumnost pri Grkih ni bila na najboljšem glasu.

v. 168 Razbojnika...: Naslovi šolskih govorov. Učitelj jih je prisiljen zamenjati z govorom na sodišču, kjer od učenčevih staršev iztoži svoj honorar.

v. 178 gospod: Mogoče gre za Plinija Starejšega. Opisana hiša spominja na Laurentinum Plinija Mlajšega, ki je imel tako bazen (Pisma 3.5.14) kot tudi sončno obednico in stebrišče (Pisma 2.17). 
v. 189 Kvintilijan: Mark Fabij Kvintilijan (c.35 - c.100?) je bil znamenit učitelj govorništva, verjetno prvi, ki je za svoje delo prejemal tudi plačo iz državne blagajne. Njegova uradna plača je znašala 100.000 sestercijev letno, zraven pa je opravljal še donosno zasebno prakso. Znan je po delu Institutio oratoria, priročniku za šolanje govornika $\mathrm{v}$ dvanajstih knjigah (ohranjen $\mathrm{v}$ celoti).

v. 191 srečni: Juvenal sarkastično pripisuje srečnemu vse lastnosti, s katerimi so stoiški filozofi označevali modrega (sapiens). Prim. Horacij, Epode 1.1.1068; Najbrž je imel tudi Juvenal v mislih ta odlomek.

v. 197 postal učitelj bo konzul: Juvenal namiguje na bivšega pretorja in senatorja Valerija Likinijana. Ta je bil izvrsten retorik, vendar pa je moral zaradi domnevnega razmerja $z$ vestalko $v$ izgnanstvo. Pod Trajanom je sprejel mesto učitelja retorike na Siciliji, svoj nastopni govor pa je (po Pliniju) začel $z$ besedami: "Kako se igraš $\mathrm{z}$ ljudmi, Fortuna: iz senatorjev delaš učitelje in iz učiteljev senatorje!" To zadnje je najbrž letelo na Kvintilijana, ki je postal senator s prijazno pomočjo Domicijanovega svaka.

v. 199 Ventidij: Publij Ventidij Bas je bil znan kot šolski primer človeka, ki mu je uspelo premagati tako nizko poreklo kot nenaklonjene okoliščine. Kot otrok je bil ujet pri Askulu in je moral korakati v triumfu Gnaja Pompeja Strabona. Nato je postal vojaški dobavitelj (čeprav ga Jüvenal v Satiri VIII zaničevalno omenja kot 'mulovodca'), leta 43 pr.Kr. pa je postal konzul ter leta 38 premagal Parte. Kmalu zatem je umrl. Tulij: Šesti rimski kralj Servij Tulij, po pripovedki sin sužnje.

v. 204 Trasimahov konec: Trasimah, Sokratov sodobnik, je bil atenski govornik, ki só ga obesili. Karina: Sekunda Karino je.Kaligula pregnal, ker se je $\mathrm{v}$ gimnaziju poniževalno izražal o tiranih. Del besedila za 205. vrstico najbrž manjka in 'ubogi', ki je dobil od Aten le kozarec trobelike, je skoraj zagotovo Sokrat.

v. 212 repu učitelja pevca: Ahilov glasbeni učitelj je bil kentaver Hiron, napol človek in napol konj.

v. 215 Palajmonu: Kvint Remij Palajmon je bil znamenit rimski slovničar iz časa Tiberija in Kaligule.

v. 221 obleke kadurške: Kadurki so bili keltsko ljudstvo v Akvitaniji, severno od Garone. Sloveli so kot izvrstni tkalci.

v. 227 Flak: Horacij. Maron: Vergilij.

v. 234 kako se je reklo: Izobraženi Rimljani so imeli navado (ki je najbrž izvirala iz helenistične Aleksandrije,) hlastati za tovrstnimi drobci znanja. To je počenjal tudi Tiberij s svojimi dvornimi učenjaki (prim. Svetonij, Tiberij 70). Posebnost Juvenalovega seznama vprašanj je $v$ tem, da noben od odgovorov ni znan.

v. 234 kralja Anhiza: Kralju Anhizu je Venera rodila Eneja, ker pa se je s svojo družico bahal, ga je Jupiter ohromil s strelo. Z Enejem, ki ga je na hrbtu odnesel iz goreče Troje, je prišel na Sicilijo in tam umrl.

v. 235 Anhemol: vojščak iz Eneide (prim. Vergilij, Eneida 10.389). Akest: sicilski kralj trojanskega rodu (prim. Vergilij, Eneida 5.73). 


\section{SUMMARY}

Translator of Juvenal's text is faced with three problems. First, he or she cannot capture the onomatopoeias, alliterations and other sound effects of the text; second, modern sense of humour has been spoiled if compared to antique one; and last, Juvenal uses numerous allusions to cultural and political life of his own time which tell the modern reader as much as the above title tells someone who is not familiar with the Slovenian literature.

First two problems cannot be helped but the last one has two possible solutions: accurate translation accompanied by a large explication, or translation de sensu explaining all proper names and destroying the wit. Neither first nor second method is entirely satisfying and the final answer is once again the Aristotelian $\mu \varepsilon \sigma o ́$ tns.

The article is followed by the Slovenian translation of Juvenal's Satire VII. 